\title{
SELETIVIDADE FISIOLÓGICA DE INSETICIDAS A VESPIDAE PREDADORES DO BICHO-MINEIRO-DO-CAFEEIRO' ${ }^{1}$
}

\author{
MARCOS RAFAEL GUSMÃO², MARCELO PICANÇO³, \\ ALFREDO HENRIQUE ROCHA GONRING ${ }^{2}$ e MARCELO FIALHO MOURA²
}

\begin{abstract}
RESUMO - Estudou-se, em laboratório, a seletividade dos inseticidas clorpirifós, deltametrina, dimetoato, ethion, monocrotofós e permetrina às vespas predadoras Apoica pallens Fab., Brachygastra lecheguana Latreille e Polistes versicolor versicolor Olivier (Hymenoptera: Vespidae) em concentrações que correspondem a $50 \%$ e $100 \%$ da dosagem recomendada para o controle do bicho-mineiro-docafeeiro, Perileucoptera coffeella Guérin-Meneville (Lepidoptera: Lyonetiidae). Deltametrina foi seletivo em favor de $P$. versicolor versicolor e $A$. pallens. O ethion foi medianamente seletivo a A. pallens e $P$. versicolor versicolor, e seletivo em favor de B. lecheguana. Os demais inseticidas não foram seletivos às vespas predadoras. A ordem crescente de tolerância das vespas a deltametrina foi: $P$. versicolor versicolor $>A$. pallens $>B$. lecheguana. Para o ethion esta ordem foi: $B$. lecheguana $>P$. versicolor versicolor $>A$. pallens. O clorpirifós, deltametrina, dimetoato, monocrotofós e permetrina apresentaram semelhante toxicidade às vespas nas duas dosagens utilizadas. O ethion, por sua vez, reduziu seu impacto sobre A. pallens e P. versicolor versicolor quando aplicado em subdosagem.
\end{abstract}

Termos para indexação: Apoica pallens, Brachygastra lecheguana, Perileucoptera coffeella, Polistes versicolor versicolor, vespas.

\section{PHYSIOLOGIC SELECTIVITY OF INSETICIDES TO WASPS PREDATORS OF THE COFFEE LEAFMINER}

\begin{abstract}
The selectivity of the insecticides chlorpyrifos, deltamethrin, dimethoate, ethion, monocrothophos and permethrin to the predatory wasps Apoica pallens Fab., Brachygastra lecheguana Latreille and Polistes versicolor versicolor Olivier (Hymenoptera: Vespidae) was studied, in laboratory, using $50 \%$ and $100 \%$ of the dosages used for controlling the coffee leafminer, Perileucoptera coffeella Guérin-Meneville (Lepidoptera: Lyonetiidae). Deltamethrin was selective in favour of $P$. versicolor versicolor and A. pallens. Ethion showed median selectivity in favour of $P$. versicolor versicolor and $A$. pallens and good selectivity to $B$. lecheguana. The other insecticides were not selective in favour of the predatory wasps. The order of tolerance to deltamethrin was: P. versicolor versicolor $>$ A. pallens $>B$. lecheguana. To ethion, the order was: B. lecheguana $>P$. versicolor versicolor $>$ A. pallens. Chlorpyrifos, deltamethrin, dimethoate, monocrothophos and permethrin presented similar toxicity to the wasps in both dosages used. On the other hand ethion reduced its impact on A. pallens and $P$. versicolor versicolor when applied in subdosages.
\end{abstract}

Index terms: Apoica pallens, Brachygastra lecheguana, Perileucoptera coffeella, Polistes versicolor versicolor, wasps.

\section{INTRODUÇÃO}

O bicho-mineiro-do-cafeeiro, Perileucoptera coffeella Guérin-Meneville (Lepidoptera:

\footnotetext{
${ }^{1}$ Aceito para publicação em 24 de maio de 1999.

${ }^{2}$ Eng. Agrôn., Dep. de Biologia Animal, Universidade Federal de Viçosa (UFV), CEP 36571-000 Viçosa, MG.

${ }^{3}$ Eng. Agr., D.Sc., UFV. E-mail: picanco@mail.ufv.br
}

Lyonetiidae), constitui-se praga-chave do cafeeiro no Brasil, ocasionando grandes perdas à cultura, em virtude da redução da área fotossintética, que podem ocasionar prejuízos de até $80 \%$ na produção de plantas (Thomaziello, 1987).

O controle químico do bicho-mineiro é empregado pela grande maioria dos cafeicultores; e o clorpirifós, deltametrina, dimetoato, ethion, monocrotofós e permetrina estão entre os principais inseticidas usados no controle dessa praga (Souza 
\& Reis, 1992; Andrei, 1996). Entre os agentes do controle biológico natural dessa praga destacam-se, entre os predadores, os himenópteros da família Vespidae. Souza (1979) constatou, no Estado de Minas Gerais, a ação predadora das vespas Protonectarina sylveirae Saussure, Polybia scutellaris White, Brachygastra lecheguana Latreille e Polistes sp. Além dessas espécies, tem-se verificado a ação predadora de outras Vespidae, como: Apoica pallens Fab. e Polistes versicolor versicolor Olivier. Gravena (1983) estudando a flutuação populacional do bicho-mineiro observou que a queda do número de larvas vivas dessa praga coincidiu com a maior atividade de B. lecheguana e Polybia occidentalis Olivier.

A ação desses inimigos naturais muitas vezes é capaz de manter a população do bicho-mineiro em densidades inferiores ao nível de dano econômico. Entretanto, o uso inadequado de inseticidas pode acarretar redução das populações dos inimigos naturais (Pedigo, 1989). Assim, para proteção dos inimigos naturais, faz-se necessário o uso de inseticidas eficientes contra a espécie-praga e seletivos aos seus inimigos naturais. A seletividade, segundo Ripper et al. (1951), pode ser classificada em ecológica e fisiológica. A seletividade ecológica relaciona-se a formas de utilização dos inseticidas de modo a reduzir a exposição do inimigo natural ao inseticida (Ripper et al., 1951). A fisiológica baseia-se no uso de inseticidas que sejam mais tóxicos à praga que a seus inimigos naturais (O'Brien, 1960).

No estudo de seletividade de inseticidas, o emprego das dosagens recomendadas para o controle das pragas permite avaliação do impacto desses produtos aos inimigos naturais no momento de sua aplicação. Já o uso de subdosagens, 50\% da dosagem recomendada para o controle da praga, possibilita a avaliação do impacto dos inseticidas quando metade de suas concentrações originais estiverem decompostas (Guedes et al., 1992; Suinaga et al., 1996).

Dada a importância das vespas predadoras no equilíbrio populacional do bicho-mineiro-do-cafeeiro, e diante da falta de estudos sobre o impacto de inseticidas sobre esses inimigos naturais, este trabalho teve como objetivo o estudo da seletividade fisiológica dos inseticidas clorpirifós, deltametrina, dimetoato, ethion, monocrotofós e permetrina em duas dosagens, às vespas sociais $A$. pallens, $B$. lecheguana e $P$. versicolor versicolor.

\section{MATERIAL E MÉTODOS}

Esta pesquisa foi conduzida no Laboratório de Manejo Integrado de Pragas da Universidade Federal de Viçosa (UFV), Viçosa, Minas Gerais, no período de agosto de 1995 a fevereiro de 1996. O delineamento experimental foi inteiramente casualizado, com quatro repetições, em arranjo fatorial $6 \times 3 \times 2$ (inseticidas $\times$ espécies $\times$ dosagens dos inseticidas), além da testemunha. Foram utilizados adultos das vespas predadoras Apoica pallens, Brachygastra lecheguana e Polistes versicolor versicolor, capturados em ninhos no campus da UFV.

Os inseticidas foram empregados em concentrações que correspondem a $50 \%$ e $100 \%$ da dosagem recomendada para o controle do bicho-mineiro-do-cafeeiro. Os inseticidas estudados e suas concentrações em mg de ingrediente ativo/mL de calda foram: clorpirifós $480 \mathrm{CE}(1,2 \mathrm{e}$ $2,4)$, deltametrina $25 \mathrm{CE}(0,00625$ e 0,0125$)$, dimetoato $500 \mathrm{CE}(1,2$ e 2,4$)$, ethion $500 \mathrm{CE}(1,25$ e 2,50$)$, monocrotofós $400 \mathrm{CE}(0,75$ e 1,50$)$ e permetrina $500 \mathrm{CE}$ $(0,125$ e 0,25$)$. Utilizou-se o espalhante adesivo $\mathrm{N}$-dodecil benzeno sulfonato de sódio $320 \mathrm{CE}$, na concentração de $30 \mathrm{~mL} / 100 \mathrm{~L}$ de calda, em todos os tratamentos (Andrei, 1996).

Folhas de cafeeiro da cultivar Catuaí foram imersas em caldas inseticidas por cinco segundos; na testemunha as folhas foram imersas em água mais espalhante adesivo. As folhas foram colocadas para secar por duas horas, e após a secagem, acondicionadas em placas de Petri $(9 \mathrm{~cm}$ de diâmetro por $2 \mathrm{~cm}$ de altura). Em cada placa foram liberados dez insetos, constituindo-se assim a unidade experimental. As placas de Petri foram levadas para estufa incubadora a $25 \pm 0,5^{\circ} \mathrm{C}$ e umidade relativa de $75 \pm 5 \%$. Vinte e quatro horas após, foram feitas avaliações do número de insetos mortos por unidade experimental, e os resultados foram corrigidos em relação à mortalidade ocorrida na testemunha usando-se a fórmula de Abbott (1925).

Os resultados de mortalidade dos insetos foram transformados em arco seno $\sqrt{(\mathrm{x} / 100)}$ para realização de análise de variância e comparação das médias pelo teste de Scott-Knott a 5\% de significância.

\section{RESULTADOS E DISCUSSÃO}

Foram detectadas diferenças significativas $(\mathrm{p}<0,05)$ na mortalidade das vespas predadoras em função dos inseticidas, espécies de vespas, dosagens e interações entre esses fatores. 
O inseticida deltametrina foi seletivo em favor de Apoica pallens com mortalidade de 28,88\% e 24,76\% na dosagem recomendada, e na subdosagem, respectivamente (Tabela 1). O ethion apresentou seletividade em favor de $B$. lecheguana e deltametrina foi o inseticida mais seletivo seguido do ethion, em favor de Polister versicolor versicolor. Foi verificada redução na toxicidade do ethion a $A$. pallens e $P$. versicolor versicolor quando aplicado em subdosagem. Os demais inseticidas apresentaram toxicidade semelhante nas dosagens utilizadas. Portanto, o impacto negativo do clorpirifós, dimetoato, monocrotofós e permetrina aos Vespidae persiste mesmo após a decomposição de metade desses princípios ativos; enquanto deltametrina apre- sentou baixo impacto a essas espécies nas duas dosagens utilizadas. Já o ethion apresentou toxicidade mediana a $P$. versicolor versicolor, que diminuiu com a decomposição de metade desse princípio ativo.

Reis \& Souza (1996) verificaram que o ethion foi eficiente no controle do bicho-mineiro-do-cafeeiro e apresentou menor impacto na redução do número de minas predadas por $B$. lecheguana, resultado que corrobora os obtidos neste trabalho. Batalha et al. (1995) também verificaram que o deltametrina foi seletivo aos percevejos predadores Podisus connexivus Bergroth e Supputius cincticeps Stal. (Heteroptera: Pentatomidae), observando-se a seguinte ordem decrescente de seletividade:

TABELA 1. Mortalidade (\%) de adultos dos predadores Apoica pallens, Brachygastra lecheguana e Polistes versicolor versicolor por inseticidas usados, em duas dosagens, no controle de Perileucoptera coffeella. Viçosa, MG. 1995/961.

\begin{tabular}{lcc}
\hline Inseticida & Dosagem recomendada & $50 \%$ da dosagem recomendada \\
\hline & & Apoica pallens \\
Clorpirifós & $100,00 \mathrm{aA}$ & $100,00 \mathrm{aA}$ \\
Dimetoato & $100,00 \mathrm{aA}$ & $100,00 \mathrm{aA}$ \\
Monocrotofós & $100,00 \mathrm{aA}$ & $100,00 \mathrm{aA}$ \\
Permetrina & $97,26 \mathrm{aA}$ & $100,00 \mathrm{aA}$ \\
Ethion & $96,65 \mathrm{aA}$ & $83,84 \mathrm{bB}$ \\
Deltametrina & $28,88 \mathrm{aB}$ & $24,76 \mathrm{aC}$ \\
\hline & \multicolumn{2}{c}{ Brachygastra lecheguana } \\
Clorpirifós & $100,00 \mathrm{aA}$ & $100,00 \mathrm{aA}$ \\
Dimetoato & $100,00 \mathrm{aA}$ & $100,00 \mathrm{aA}$ \\
Monocrotofós & $100,00 \mathrm{aA}$ & $100,00 \mathrm{aA}$ \\
Permetrina & $100,00 \mathrm{aA}$ & $100,00 \mathrm{aA}$ \\
Deltametrina & $100,00 \mathrm{aA}$ & $97,50 \mathrm{aA}$ \\
Ethion & $9,32 \mathrm{aB}$ & $2,50 \mathrm{aB}$ \\
\hline & \multicolumn{2}{c}{ Polistes versicolor versicolor } \\
Clorpirifós & $100,00 \mathrm{aA}$ & $97,50 \mathrm{aA}$ \\
Dimetoato & $100,00 \mathrm{aA}$ & $100,00 \mathrm{aA}$ \\
Monocrotofós & $100,00 \mathrm{aA}$ & $100,00 \mathrm{aA}$ \\
Permetrina & $100,00 \mathrm{aA}$ & $95,00 \mathrm{aA}$ \\
Ethion & $22,78 \mathrm{aB}$ & $10,00 \mathrm{bB}$ \\
Deltametrina & $7,05 \mathrm{aC}$ & $7,50 \mathrm{aB}$ \\
\hline A & \multicolumn{2}{c}{}
\end{tabular}

${ }^{1}$ As médias seguidas pela mesma letra, minúscula na linha e maiúscula na coluna, não diferem entre si, pelo teste de Scott-Knott a p<0,05. 
deltametrina $>$ malatiom $>$ permetrina $>$ carbaril. Picanço et al. (1996) também verificaram que deltametrina foi mais seletivo que o fentiom, malatiom e cartap aos percevejos $P$. connexivus Bergroth e S. cincticeps Stal., predadores de Dione juno juno Cr. (Lepidoptera: Heliconidae) em cultura de maracujazeiro.

As razões da seletividade do deltametrina e ethion obtidas neste trabalho podem advir de três mecanismos: menor taxa de penetração desses produtos na cutícula, maior taxa de metabolização do composto pelo inimigo natural do que pela praga, ou alterações no alvo de ação dos princípios ativos no inimigo natural (Yu, 1987, 1988). O caráter lipofílico de alguns inseticidas associado à espessura e composição lipídica da cutícula dos insetos é responsável pela maior penetração do produto na cutícula e sua translocação até o alvo de ação (Hollingworth, 1976; Hoy, 1990; Guedes et al., 1992). Yu (1987, 1988) relatou que para Podisus maculiventris Say (Heteroptera: Pentatomidae), a metabolização dos piretróides por oxidases microssomais e esterases acarreta maior desintoxicação desses inseticidas nesse percevejo predador do que em suas presas. A menor sensibilidade da acetilcolinesterase do predador a inseticidas organofosforados do que a de espécies-praga pode ser responsável pela seletividade desses inseticidas (Zon \& Helle, 1966; Tripathi \& O'Brien, 1973; Voss, 1980). A insensibilidade do sistema nervoso central e a sensibilidade das enzimas (Na-K)-ATPase e $\mathrm{Mg}_{2}$-ATPase estão intimamente relacionadas à ação neurotóxica de piretróides, como deltametrina e permetrina (Sun et al., 1990; Zhao et al., 1992; Leng \& Xiao, 1995).

$P$. versicolor versicolor foi a espécie mais tolerante à deltametrina, seguida por A. pallens, medianamente tolerante, e por $B$. lecheguana, a menos tolerante. $B$. lecheguana foi mais tolerante a ethion, seguida por $P$. versicolor versicolor, enquanto $A$. pallens foi a menos tolerante. Os inseticidas clorpirifós, dimetoato, monocrotofós e permetrina foram altamente tóxicos às três espécies de vespas (Tabela 1).

As diferenças na tolerância entre as espécies de vespas devem-se aos mesmos mecanismos de seletividade já descritos. Possivelmente, as diferenças de tolerância dos Vespidae a deltametrina e ethion estejam associadas a diferenças na degradação destes por enzimas que participam da degradação de inseticidas, como as oxidazes microssomais (Yu, 1987, 1988). A eleição desse mecanismo baseia-se na lipofilicidade dos compostos estudados e no fato de que inseticidas de determinado grupo possuem o mesmo alvo de ação. O fato de este mecanismo sobrepor-se ao de diferenças na taxa de penetração dos compostos via cutícula e ao de alterações no alvo de ação dos inseticidas deve-se à relação indireta entre lipofilicidade e tolerância apresentada pelos piretróides, deltametrina e permetrina e às diferenças no comportamento tóxico dos organofosforados, ethion e monocrotofós, que têm o mesmo alvo de ação.

Sabe-se que a lipofilicidade é inversamente proporcional à solubilidade do inseticida em água, cujos compostos mais lipofílicos, pela semelhança química com a cutícula, geralmente penetram em maiores taxas no corpo do inseto. Assim, se tal mecanismo fosse o que determinasse as diferenças de tolerância das vespas, era de se esperar que estas fossem mais tolerantes a permetrina (1 ppm de solubilidade em água) do que a deltametrina (menos de $0,002 \mathrm{ppm}$ de solubilidade em água). Entretanto, foi verificada maior tolerância à deltametrina do que à permetrina. Se as diferenças na tolerância das vespas fossem causadas por alterações no alvo de ação dos compostos, esperava-se que estas apresentassem o mesmo nível de tolerância a inseticidas de mesmo grupo, os quais possuem o mesmo alvo de ação. Porém, verificou-se maior tolerância das vespas a ethion do que a monocrotofós, embora estes organofosforados apresentem o mesmo alvo de ação a acetilcolinesterase (O’Brien, 1976; Eto, 1990).

Tal hipótese também é fundamentada nas observações feitas por Layton et al. (1994) e Picanço et al. (1997). Estes últimos autores verificaram que a maior tolerância de fêmeas do percevejo predador P. nigrispinus a inseticidas do que machos dessa espécie esteve associada ao maior volume corporal das fêmeas, o que as tornam menos expostas aos inseticidas dada a menor área específica do corpo. Já Layton et al. (1994) observaram variações nas proporções de alquenos da camada lipídica da cutícula da vespa predadora Polistes metricus Say. (Hymenoptera: Vespidae), as quais podem estar as- 
sociadas a diferenças na taxa de penetração dos inseticidas na cutícula do inseto. As observações desses autores evidenciam que o mecanismo de penetração de inseticidas via cutícula do inseto pode determinar ou não a tolerância do inseto ao inseticida. Porém no presente trabalho tal mecanismo não foi o determinante da tolerância das espécies, uma vez que, das espécies estudadas, B. lecheguana é a que apresenta menor volume corporal, por seu corpo possuir a maior área específica, característica que lhe proporciona maior contato com os resíduos inseticidas. Entretanto, esta foi a espécie mais tolerante a ethion. Quanto a $A$. pallens, foi a espécie que apresentou maior suscetibilidade aos inseticidas em geral, cujo volume corporal se assemelha ao da espécie $P$. versicolor versicolor, considerada a mais tolerante.

\section{CONCLUSÕES}

1. Deltametrina apresenta seletividade em favor dos predadores Apoica pallens e Polistes versicolor versicolor; ethion é seletivo em favor do predador Brachygastra lecheguana e medianamente seletivo em favor de A. pallens e Polistes versicolor versicolor; clorpirifós, dimetoato, monocrotofós e permetrina são altamente tóxicos às três espécies de vespas predadoras.

2. O clorpirifós, deltametrina, dimetoato, monocrotofós e permetrina apresentam toxicidade semelhante às vespas nas duas dosagens utilizadas; o ethion reduz seu impacto sobre $A$. pallens e $P$. versicolor versicolor, quando ocorre decomposição de metade do princípio ativo.

3. Entre as três espécies de Vespidae, $P$. versicolor versicolor é a espécie mais tolerante a deltametrina, seguida por $A$. pallens e por $B$. lecheguana, que é a mais suscetível ao inseticida; a espécie mais tolerante ao ethion é $B$. lecheguana, seguida por $P$. versicolor versicolor e $A$. pallens.

\section{AGRADECIMENTOS}

Ao CNPq e FAPEMIG, pelas bolsas concedidas, e ao Programa Nacional de Pesquisa e Desenvolvimento do Café, pelo financiamento desta pesquisa e pelas bolsas concedidas.

\section{REFERÊNCIAS}

ABBOTT, W.S. A method of computing the effectiveness of an insecticide. Journal of Economic Entomology, Lanham, v.18, n.3, p.265-267, 1925.

ANDREI, E. Compêndio de defensivos agrícolas. 5.ed. São Paulo : Andrei, 1996. 506p.

BATALHA, V.C.; ZANUNCIO, J.C.; PICANÇO, M.C.; SEDIYAMA, C.S. Seletividade de inseticidas aos predadores Podisus nigrispinus (Dallas, 1851) e Supputius cincticeps (Stal, 1860) (Heteroptera: Pentatomidae) e a sua presa Lepidoptera. Revista Árvore, Viçosa, v.19, n.3, p.382-395, 1995.

ETO, M. Biochemical mechanisms of insecticidal activities. In: BOWERS, W.S.; EBING, W.; MARTIN, D. (Eds.). Chemistry of plant protection. Berlin : Spring, 1990. v.6, p.67-68.

GRAVENA, S. Táticas de manejo integrado do bicho mineiro do cafeeiro Perileucoptera coffeella (GuérinMéneville, 1842): I- Dinâmica populacional e inimigos naturais. Anais da Sociedade Entomológica do Brasil, Jaboticabal, v.12, n.1, p.61-67, 1983.

GUEDES, R.N.C.; LIMA, J.O.G.; ZANUNCIO, J.C. Seletividade dos inseticidas deltametrina, fenvalerato e fenitrotion para Podisus connexivus (Heteroptera: Pentatomidae). Anais da Sociedade Entomológica do Brasil, Porto Alegre, v.21, n.3, p.339-346, 1992.

HOLLINGWORTH, R.M. The biochemical and physiological basis of selective toxicity. In: WILKINSON, C.F. (Ed.). Insecticide biochemistry and physiology. New York : Plenum, 1976. p.431506.

HOY, M.A. Pesticide resistance in arthropod natural enemies: variability and selection responses. In: ROUSH, R.T.; TABASHNIK, E. (Eds.). Pesticide resistance in arthropods. New York : Chapman and Hall, 1990. p.203-236.

LAYTON, J.M.; CAMANN, M.A.; ESPELIE, K.E. Cuticular lipid profiles of queens, workers, and males of social wasps Polistes metricus Say are colonyspecific. Journal of Chemical Ecology, New York, v.20, n.9, p.2307-2320, 1994.

LENG, X.F.; XIAO, D.Q. Effect of deltamethrin on protein phosphorylation of housefly brain synaptosomes. Pesticide Science, Barking, v.44, n.1, p.88-89, 1995.

Pesq. agropec. bras., Brasília, v.35, n.4, p.681-686, abr. 2000 
O'BRIEN, R.D. Acetylcholinesterase and its inhibition. In: WILKINSON, C.F. (Ed.). Insecticide Biochemistry and Physiology. New York : Plenum, 1976. p.271-296.

O'BRIEN, R.D. Toxic phosphorus esters. New York : Academic, 1960. 434p.

PEDIGO, L.P. Entomology and pest management. New York : Macmillan, 1989.646p.

PICANÇO, M.C.; GUEDES, R.N.C.; BATALHA, V.C.; CAMPOS, R.P. Toxicity of insecticides to Dione juno juno (Lepidoptera: Heliconidae) and selectivity to two of its predaceous bugs. Tropical Science, Oxford, v.36, n.1, p.51-53, 1996

PICANÇO, M.; RIBEIRO, L.J.; LEITE, G.L.D.; ZANUNCIO, J.C. Seletividade de inseticidas a Podisus nigrispinus predador de Ascia monuste orseis. Pesquisa Agropecuária Brasileira, Brasília, v.32, n.4, p.369-372, 1997.

REIS, P.R.; SOUZA, J.C. Manejo integrado do bicho mineiro, Perileucoptera coffeella (Guérin-Méneville) (Lepidoptera: Lyonetidae), e seu reflexo na produção de café. Anais da Sociedade Entomológica do Brasil, Londrina, v.25, n.1, p.77-82, 1996.

RIPPER, W.E.; GREENSLADE, R.M.; HARTLEY, G.S Selective insecticides and biological control. Journal of Economic Entomology, Lanham, v.44, n.4, p.448449,1951

SOUZA, J.C. Levantamento, identificação e eficiência dos parasitos e predadores do "bicho mineiro" das folhas do cafeeiro Perileucoptera coffeella (Guérin-Méneville, 1842) (Lepidoptera: Lyonetiidae) no Estado de Minas Gerais. Piracicaba : USP-ESALQ, 1979. 91p. Dissertação de Mestrado.

SOUZA, J.C.; REIS, P.R. Bicho mineiro: biologia, danos e manejo integrado. Belo Horizonte : EPAMIG, 1992. 28p. (Boletim Técnico, 37).

SUINAGA, F.A.; PICANÇO, M.; ZANUNCIO, J.C.; BASTOS, C.S. Seletividade fisiológica de inseticidas a Podisus nigrispinus (Dallas, 1851) (Heteroptera: Pentatomidae) predador de lagartas desfolhadoras de eucalipto. Revista Árvore, Viçosa, v.20, n.3, p.407414, 1996.

SUN, Y.Q.; YUAN, J.G.; LI, J.; HE, F.Q.; LIU, B.W.; WANG, J.; GONG, K.Y. The resistance mechanism of housefly against pyrethroids. Acta Entomologica, Prague, v.33, n.3, p.265-273, 1990.

THOMAZIELLO, R.A. Manejo integrado de pragas, doenças e plantas daninhas em café. In. SIMPÓSIO INTERNACIONAL DE MANEJO INTEGRADO DE PRAGAS, DOENÇAS E PLANTAS DANINHAS, 1., 1987, Campinas. Anais. Campinas : ANDEF, 1987. p.155-170.

TRIPATHI, R.K.; O'BRIEN, R.D. Insensitivity of acetylcholinesterase as a factor in resistance of houseflies to the organophosphate rabon. Pesticide Biochemistry and Physiology, San Diego, v.3, n.4, p.495-498, 1973.

VOSS, G. Cholinesterase autoanalysis: a rapid method for biochemical studies on susceptible and resistant insects. Journal of Economic Entomology, Lanham, v.73, n.2, p.189-192, 1980.

YU, S.J. Biochemical defense capacity in the spined soldier bug (Podisus maculiventris) and its lepidopterous prey. Pesticide Biochemistry Physiology, San Diego, v.28, n.3, p.216-223, 1987.

YU, S.J. Selectivity of insecticides to the spined bug (Heteroptera: Pentatomidae) and its lepidopterous prey. Journal of Economic Entomology, Lanham, v.81, n.1, p.119-122, 1988.

ZHAO, W.Q.; FENG, G.L.; SUN, Y.Q.; SHAO, Y. An important resistance mechanism of housefly to DDT and pyrethroides-CSN insensitivity. Acta Entomologica, Prague, v.35, n.4, p.393-398, 1992.

ZON, A.Q.V.; HELLE, W. A search for lenkage between genes for albinism and parathion resistance in Tetranychus pacificus Mcgregor. Genetica, Dordrecht, v.37, n.1, p.181-185, 1966. 